\title{
Mental Health, Dynamic Psychology and Personal Management
}

\author{
LUO Guicheng \\ Xi Jinping Thoughts Research Institute, Bengbu Bengbu University, Bengbu 233000, China
}

\begin{abstract}
Mental health standards are flexible, varying along with different regional culture as well as different age. The goals of mental health management are, in a changing environment, to stabilize mental state, improve mental capacity, create good outer mental environment and refrain from abnormal mentality. Mental quality structure is made up of mental strength, flexibility, recovery capacity, balance ability, dexterity and intelligence. Mental exercise helps to overcome mental inertia and enhance mental quality. The focus for youth mental exercise is to breed mental capacity, while that of adult is to overcome negative mental inertia. Individual's emotion interacts with environment, which is dominated by law of dyeing vat, as is also the most important reason for dynamic mental management. Different environments need different mental health strategies, which is decision by circumstance orientation for mental health management. Li Zongwu's mental model of thick and dark heart as well as Wei Xiaobao's dynamic mental model is applied mental model under violence society, the beneficial ingredients of which should be adopted, the negative value within them should be abandoned. Innovations, (1) researched mental quality in a changing social environment, as is viewed as the main context of dynamic psychology, also the characteristic of this paper, (2) proposed the concept of mental exercise, (3) redefined the concept for mental inertia, also offered solutions for it, (4) proposed a fundamental law for dynamic psychology, law of dyeing vat, (5) proposed the concept of optimum emotion, the concept of decision by circumstance orientation, (6) researched several practical mental model, such as Empty Cup mental model, Li Zongwu's thick and dark heart model, Wei Xiaobao's flexible mental model. Methods, (1) literature research, (2) exemplifications, (3) simple statistics.
\end{abstract}

Keywords: mental quality structure; mental exercise; mental inertia; law of dyeing vat; optimum emotion; decision by circumstance orientation

\section{Introduction}

Mental quality, an endogenous attribute of personal quality, together with physical quality, is the resource condition of personal development, also the basis of personal learned quality or ability [1, P1-2]. People's minds interact with environment, it is a kind of progress to research how to improve people's mental state in a changing environment than to study people's psychology while not paying concern to the real society, as is an important content of mental health management, also the focus of dynamic psychology research.

\subsection{On Mental health Management}

\subsubsection{Goals of mental health management}

Mental health is vital to the sustainable development of people, for, when the mental quality is zero, we can think that the whole quality of people is $0[1, \mathrm{P} 2]$. The thought of mental exercise put forward at the end of the 20th century and the beginning of the 21 st century is of great significance in the field of mental research, which makes people pay equal attention to the health of mind as well as physical body from only emphasizing the physiological health. Mental health and physical health interact with each other, and mental activities are accompanied by biological energy expenditure, determine the physiological state, which provides theoretical basis for Qigong therapy, hypnotic therapy and religious therapy. Mental management can also reduce the immediate outbreak of irrational emotions of residents, optimize the mental environment of social groups, and improve the social mental welfare.

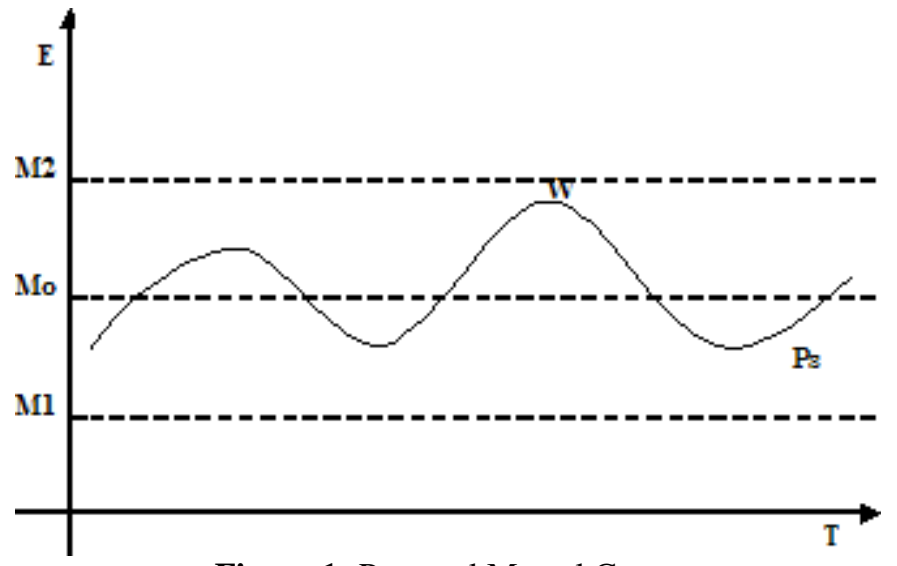

Figure 1: Personal Mental Care

Personal management and organizational management are the process of achieving the objective of a subject in a dynamic environment [2]. The same is mental health management, people's mind is influenced by the environment. Mental management and mental exercise are mental autonomous guidance under a dynamic environment, to improve mental ability or to stabilize mental state, create a good external mental environment, prevent mental anomaly or failure, to provide the mental guarantee for individual's development in a dynamic environment. The difference of individual mental quality is judged by the reaction quality to environment change. It is meaningful to discuss the mental management in a changing environment. The study of the science of mental health and mental management in a changing environment belongs to dynamic psychology.

\subsubsection{Stabilize mental state}

Mental quality, the endogenous quality of personal quality, 


\section{International Journal of Science and Research (IJSR) \\ ISSN: 2319-7064}

ResearchGate Impact Factor (2018): 0.28 | SJIF (2018): 7.426

is the core of personal quality structure [1, P1-2]. It is an important goal of mental management to stabilize the mental state and control the mental change within a certain amplitude in dynamic environment (Fig.1), avoiding great rise and fall of mental state, fencing off mental failure, mental crisis or mental abnormality, provides a stable internal mental environment or available mental resources for individual daily life and work. Fig.1, the horizontal axis $\mathrm{T}$ represents time, and the vertical axis represents the emotional state $\mathrm{E}$ of an individual without mental disorder, E can be measured in terms of the biological energy consumption or the physical damage from mental activity per unit of time, curve Ps indicates the track of individual emotion along time, Mo denotes median emotion of social group or rational emotion, M1 indicates the bottom line of depressed emotion of social group, M2 indicates excitement peak line of social group. The mental management avoids the mental state approaching to the bottom line M1 or the peak line M2. An excessive low spirit consumes the physical energy negatively, affects the subject's normal cognition and judgment, affects daily life as well as work quality, or causes the organic injury to physiology, results in negative economic efficiency in personal development. Excessive excitement also leads the subject make irrational decisions, often resulting in significant economic losses or mental trauma. Negative emotions also spread, impact the mental state of a group, e.g, "a weep makes all sad, a merry lights up all hearts".

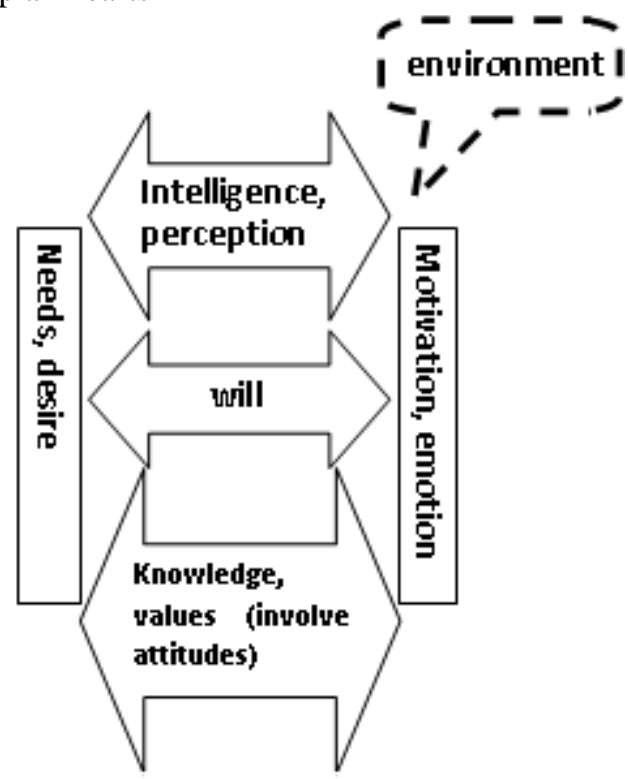

Figure 2: The circuit of psychological system

\subsubsection{Improve mental capacity}

What to be managed in mental management? Intelligence, perception, desire, or emotion, will? Mental management, combined with external changing environment, manages the whole mental system consisting of various mental elements, to ensure the quality of the inner mental environment and improve the mental ability of the subject. Intelligence, perception, desire, emotion and will are all the object of mental management. In a peaceful social environment, a subject of with normal mind, the focus of mental management is to manage desire, so that desire does not expand excessively, to avoid mental overheating. For the external environment, the focus of mental management is to improve the subject's capacity to resist mental stress, enhance anti-disturbance ability to avoid excessive emotional excitement or depression. According to Maslow's theory, people have five needs: physiological needs, security needs, love and belongingness needs, social respect needs, self-actualization needs. Need is the root of desire. The degree of desire satisfaction, the value for desire, the attitude towards environment will decide emotion, the quality of emotion will decide the whole mental state. Intelligence, perception, desire, emotion, and will are an interacting system (Fig.2). Fig.2 shows that, after environment information input, there are three channels of interaction between left side desire and right side motivation. The first is intelligence, perception, the second is will, and the third is knowledge, values, involving attitudes towards the environment. From the observation of internal mental factors, also the three channels to control personal emotion, and these three channels are relevant.

Combined with Taylor, James's study [3], the structure of mental ability covers: (1) strength, the important index of strength is will power, (2) flexibility, or social compatibility, that is, reasonable compatibility or concession to other social members, mental flexibility can often prevent irrational outbreak of emotion. (3) recovery capacity, that is, the ability to restore normal emotions immediately after being attacked, flexibility and recovery capacity together can be called mental resilience. (4) dexterity, that is, the speed and precision of response to environmental change, and individual perception will affect mental dexterity. (5) the ability of balance, that is, the ability to maintain mental balance at different levels of social energy, which is related to toughness. For example, being a billionaire rich as Bill Gates, heart happy, and being a beggar on the street, also happy. Deng Xiaoping as a national premier, heart balanced; he squatted in a bullpen during 10 Years Cultural Revolution, heart also peaceful. (6) intelligence.

Personal knowledge structure, values and family background affect their mental ability. Knowledge structure involves empirical knowledge from practice, often the specific knowledge of individuals, also the source of "ancestor's secret recipe".

In addition, it is also an important goal of mental management to let good emotion or mental state affect the mental state of group, improve the external mental environment and avoid the internal mental abnormality.

\subsection{Gauge and comparison of mental capacity}

\subsubsection{Gauge of mental capacity}

There are two methods in the quantitative study of mental ability. One is the international standard person method [1, P6], that is, a standard person is determined every 50 years worldwide, with a score of 100 according to his mental quality. Other subjects were compared with the standard person to obtain a value of mental ability. For example, taking a soldier of U.S Special Forces as the standard person for mental quality, his mental quality is 100 points. When the human resources department inspects its employees, it can compare the staff with the special soldier of U.S. This method is derived from the idea of an international meter device for length measurement.

Volume 9 Issue 1, January 2020 


\section{International Journal of Science and Research (IJSR) \\ ISSN: 2319-7064}

ResearchGate Impact Factor (2018): 0.28 | SJIF (2018): 7.426

The second method of quantitative study of mental ability is subjective assignment method, that is, to assign benchmark score to six indexes of mental ability, and then ask experts to score the subject (Tab.1). Deng Xiaoping, chief designer of the first round of Chinese reform, scored 109 points, much higher than the standard, because of his special experience. The average person is between 60 and 90. If the mental ability is below 60 points not changing, their personal welfare in the short or long term will certainly run below the social average.

Table 1: Subjective evaluation for mental capacity

\begin{tabular}{|c|c|c|c|c|c|c|c|}
\hline & strength & flexibility & recovery capacity & dexterity & balance capacity & intelligence & total \\
\hline benchmark & 18 & 17 & 15 & 15 & 17 & 18 & 100 \\
\hline Deng- Xiaoping & 20 & 17 & 16 & 18 & 17 & 21 & 109 \\
\hline
\end{tabular}

\subsubsection{Comparison of mental capacity}

According to the measurement of mental ability, human resources departments can compare the mental ability of different employees, and researchers can also compare the qualities of different social groups. The results are used to assess the efficiency of training or the quality of education in a country (Tab.2).

Table 2: Comparison of mental capacity

\begin{tabular}{|c|c|c|c|c|c|c|c|}
\hline & strength & flexibility & recovery capacity & dexterity & balance capacity & intelligence & total \\
\hline benchmark & 18 & 17 & 15 & 15 & 17 & 18 & 100 \\
\hline Bob & 18 & 17 & 15 & 15 & 16 & 18 & 99 \\
\hline Jack & 18 & 17 & 15 & 15 & 17 & 18 & 99 \\
\hline African- teacher & 18 & 15 & 10 & 10 & 15 & 15 & 83 \\
\hline Euro-doctor & 18 & 16 & 12 & 13 & 15 & 15 & 89 \\
\hline Russia warrior & 18 & 15 & 11 & 13 & 14 & 15 & 86 \\
\hline
\end{tabular}

\subsection{Mental inertia}

The important task of adult mental management is to overcome mental inertia and prevent mental aging. Thinking inertia, mental inertia and addiction, which are highly concerned by society, What is their relationship?

Definition 1, mental inertia, it refers to a subject's mental dependence upon a certain behavior or way of thinking in life and work, which means if there is no external stimulus or internal compulsive influence, the mind of the subject will move along the original way. Mental inertia includes thinking inertia, life habits, work habits, addiction and hobby.

That is, the thinking inertia is a kind of mental inertia, and the common habits of life and work are related to mental inertia. Mental inertia can be positive or negative, depending on environmental conditions, such as habit or addiction. Once the habit of getting up early is formed, there will be mental conflict when not getting up early, and getting up early is also beneficial to work and exercise. However, if the subject suffers from a pathological change in his health, getting up early may lead to a lack of sleep, which is not conducive to the recovery of subject's health. Mental inertia is not easy to change, because it takes costs to make a change, including the increase of biological energy consumed by the change of mental activity path. In short run, it is cheaper to operate in the same way than to shift into a new one, that is why social members are happy to persist to old manner. Mental inertia, embodied in a society, is institutional inertia. For the cost of changing the inertia, the society has a path dependence on the original institutional order. This path dependence has little cost in short term, while hinders innovation and the improvement of overall benefit in long run. Currently, the development of international social integration is accelerating. Market changes often demand social members or organizations to break inertia to run their work. It is easy to fail by sticking to traditional manners. Mental inertia is also the main point of attack or defense for both sides of the war, no matter a hard war or a soft war, the mental inertia of the other side and its own will be highly concerned.

Generally, addiction is harmful to health, mental inertia and the formation of addiction are not only related to inertia itself, but also to a specific external environment. Getting in the same external environment for a long time, one's mind will tend to have greater inertia or addiction. The key of abstinence from an addiction lies in self-establishing of mental will, cutting off the social connection of addiction or changing the external environment arousing addiction, preventing the relapse of addiction. Bad mental inertia may also develop into mental abnormalities, such as in the late 1990s in a rural county in western Hunan province, China, a young man had a habit of stealing the bra of neighbor women. Mental inertia can also be employed to explain incest and the prominent phenomenon of mental abnormality homosexuality in western countries. It should be pointed out that workaholics are also the extreme case of mental inertia and belong to addiction, which has a great damaging effect upon health and is not conducive to the sustainable development of human beings [1, P12]. Mental inertia is also useful in explaining the mental trauma of war, for instance, the mental barrier caused by the Iraq war to some American warriors, which is related to mental inertia.

\subsection{Mental exercise}

Mental exercise is a new concept, including intelligence exercise, perception exercise, strength exercise, flexibility exercise, and other mental ability exercise. For an individual with a normal mind, in his growing period, he should focus on forming eligible mental abilities, developing intelligence, enhancing willpower, and forming positive mental inertia, such as good study habits, labor habits, and physiological 


\section{International Journal of Science and Research (IJSR) \\ ISSN: 2319-7064}

ResearchGate Impact Factor (2018): 0.28 | SJIF (2018): 7.426

exercise habits. the habit of respecting the human right of others and social justice, the habit of caring for environment; improve dexterity, overcome negative mental inertia, such as avoid sex addiction, internet addiction, smoking, alcohol addiction. Although the proposal of mental exercise does not mean that the Olympic Games with mental ability contest will emerge immediately in international community, it gives an important enlightenment to the development strategy of social human resources: mental quality is not only important, just like the physical body, it demands a fixed amount of time to exercise. Mental exercise is an important part of mental management. It avoids people from becoming addicted to sex addiction, smoking addiction, alcohol addiction, entertainment, other behaviors or material addiction, and avoids people indulging in instant happiness of material or behavior, addiction would lead to the loss of long-term personal or family welfare. With mental training, the number of weak and lax residents would be reduced, social civilization promoted.

\subsubsection{Strategy of mental exercise}

The strategy of mental training includes: (1) managing positive external environment, such as positive family education, school education and social education. The low or high mental ability is directly related to the external environment for mental ability growth. The poor external environment, such as family violence, low knowledge stock of family members, social violence, inability to consume or lack of school education, all can easily lead to low mental capacity. The common symptoms of low mental capacity in Chinese adolescents are, low ability to resist environmental negative signals, weak will performance, or mental rigidity or stubbornness that does not consider environmental interference factors, or low resilience and low balance ability when they are unable to withstand blows. These indicators directly lead to the decline of the long-term development curve of individuals [1, P11]. The control upon the external environment by the subject is limited, but the subject can do something. (2) adhere to physiological exercise to form a good physical fitness. Good physiological ability does not necessarily imply good mental ability, but good physiological ability is helpful to improve mental ability. Good physical potential is necessary to form strong willpower, form high intelligence, keep sensitive feeling and perception, physiology is the carrier of psychology. Without physical and material support, mental ability can not develop. Regular physical exercise for more than one hour a day has dual functions, both physical exercise and mental exercise. (3) learning. The purpose of learning is to make the brain's cognition upon the world consistent with reality, and to provide the subject with a possible solution to problems. Knowledge is an important channel to improve the mental ability. (4) religion belief. Pupils in countries with religious taboos, such as China, may join legitimate party organizations. As a whole, the scientific basis of religion has been largely confirmed, in fact, from the perspective of psychology and sociology, religion is a science more authentically. Religion helps people reasonably deal with the relationship between personal interests and other people's rights, social rights, their desires. Daily praying, meditation and repentance are good ways to exercise moral cultivation. To young people, they are also the best way to develop intelligence, such as Qigong in
China, yoga in India, and hypnotism of the western world (5) social practice. The real mental ability is developed in social practice. The mental ability of Deng Xiaoping, the second generation core of CPC, outperformed ordinary people, which was not built by common exercise, but grown up by his revolution practice, cultivated by political struggle. We think that good mental ability comes from the combination of study and practice, of which school education could only account for $30 \%$.

Young people's mental exercise is focused on the formation of ability, adults' mental exercise is focused on preventing mental aging and mental ability withering, to maintain sensitivity, preventing mental inertia from becoming an obstacle for decision-making, avoid mental inertia bringing losses upon society or family. For example, politicians should overcome institutional inertia to promote innovation and reform, and prevent institutional inertia from hindering the progress of social civilization. Institutional inertia, in addition to the interest dependence, is also reflected at the opposition groups' emotional inertia and thinking inertia upon the old system. Adolescent's mental exercise is mainly oriented toward inner world growth exercise, adults' mental exercise are mainly oriented to the environment. Mental exercise strategies for the adolescent are also applicable to the adulthood.

\subsubsection{Content of mental exercise}

The key content of mental exercise is the six indexes of mental ability (Tab.1).

(1) strength training, that is, the exercise for strong willpower. Special mental environment can be created to exercise willpower, such as imitation of the 2008 Chinese Wenchuan earthquake environment for willpower training, imitation of the 1998 Chinese flood environment for willpower training, imitation of the Sahara desert environment survival training, imitation of survival training in a fire disaster, imitation of forest lost training, imitation of suffering rogue attack training, imitation of coming across 9.11 training, imitation of love failure, imitation of single night guard at skyscrapers, imitation of suffering hunting from the feudal political rascals, imitation of encountering naked beauty on bed, imitation of hungry guy encountering hot pot of baby duck, imitation of drunkard encountering Maotai, imitation of encountering noise attack, experiencing a city clerk cleaning dung, experiencing an desert island life of Robinson Crusoe. (2) flexibility training. Design beauty trap for public relations or assessment upon staff, act as beggars or other weak people to awaken compassion training, act as the elder's kindness caring for the younger generation, act as senior leaders with a broad-mind, design a big windfall to conduct staff assessment or public relations training, act as a political enthusiast to lobby for political reform, touching cry training, charming smile training, design beauty embrace training, experiencing Han Xin crawling across hooligan's crotch insult (Han Xin was the major general of Emperor Liu Bang in Chinese Han Dynasty). (3) recovering ability training. A simulated mental environment could be created to train their mental recovering ability. Imitation of father's death training, imitation son's car accident, imitation of wife being raped by gangster, imitation of newborn baby being

\section{Volume 9 Issue 1, January 2020}




\section{International Journal of Science and Research (IJSR) \\ ISSN: 2319-7064}

ResearchGate Impact Factor (2018): 0.28 | SJIF (2018): 7.426

swapped in hospital, imitation of car being stolen, imitation of being criticized by seniors in public, imitation of papers being plagiarized, intercepted or blocked on internet, imitation of luxury houses being blown up, imitation of being publicly humiliated by lovers. (4) balance ability training. Imitation of Huang Guangyu's prison life (Huan Guanyu, a Chinese tycoon in 2010s), imitation of a beggar's winning hundreds of millions of lottery tickets, imitation of election campaign victory, imitation of a bankruptcy in Wall Street financial storm, and imitation of winning beauty $\mathrm{Li}$ Jiaxin's sweet kiss (Li Jiaxin, a Chinese beauty in 2000s). The balance ability is related to recovering ability, recovery ability mainly refers to the ability to restore normal state after mental attack or trauma, and the balance ability denotes maintaining a normal state of mind after the social status significantly leaps forward. (5) dexterity training. That is, to train the mental ability of quick reaction and accurate judgment, which is related to perception knowledge. (6) intelligence training. Intelligence depends on geneticness and education. Teenagers believing in religion, practicing Qigong, Yoga, hypnosis can significantly improve their IQ, but must have guidance from professional teacher, no violation of national laws.

The division of the six indexes of mental ability is not absolute. Some simulation environments have many training functions, such as Robinson Crusoe waste-island mode, which is not just to exercise the willpower of the subject. Six mental abilities are also relevant. The operation can be simplified by one or more of them, for example, in the first half of the year, the focus is on willpower training, and in the second half of the year, mental flexibility can be trained. Exercise should be combined with the strategy in previous study, attention should be paid to conjoining practical experience, theoretical learning, and physical exercise.

Regular and scientific mental exercise can effectively prevent mental abnormality and mental failure. It must be emphasized that mental ability mainly depends on social practice, while campus learning and training is only an introduction and enlightenment.

\subsection{Emotion management}

\subsubsection{Emotion management skills}

The important performance of mental ability is the ability to control emotion, and human emotion depends on environment and the inner mental response to environment. According to the research of Lazarus and Folkman [4], there are four factors in stress reaction: stress source, stress medium, stress reaction process, and stress reaction result. Emotional management can be started from the first three elements: (1) controlling the source of emotion, that is, changing the external environment of psychology, improving the original environment or moving from a bad mental environment to another good mental environment. For example, when a foreign investor comes to China for investment, he finds that corruption in China leads to high transaction costs and affects his business mood, then he either withdraw money to India or other countries, or succumb to bribe. Psychologists suggest that people should frequently listen to music, sing, watch movies, climb mountains, chat and read to control the source influencing mood . (2) control emotional media and emotional reaction process. "I exist because I am thinking”, “existence because of being perceived", from the chain of mental emotional responses, these sights are correct. Some emotion caused by external stimuli is due to the corresponding response of subject's mental system. If subject's mental system does not react to the environmental stimuli, the emotion will not appear. Here are two dialogues:

\section{Dialogue 1}

Waiter D: You really have a good appetite!

Customer A: Hoho, this braised meat is fresh and tender! Dialogue 2

Waiter D: Why can you not react at all?

Customer A: The company suffered a big loss recently!

Why do the same waiter and consumer have different moods? "existence because of being perceived." the mental system of customer A reacts differently to D's signals, so emotional outcomes are different. Here, to A's mental system, because external stimuli "company losses" interferes with D's food stimuli, A cannot sense D's food signals, where A's non-perception upon braised meat is passive. In fact, A can also actively not sense D's food signals. For example, in order to treat his hyperlipidemia, A decides to treat his addiction upon braised meat and exercise his willpower. He specially goes to a street of gourmet food street and forcefully suppresses his mental system's reaction to street food signals, keeps saying "braised meat harmful to health", "braised meat harmful to health", and actively undergoes mental intimation to overcome the environmental stimuli.

Emotion management is more difficult than theoretical analysis. When the appetite of diner A reaches the peak of fig. 1 by internal physiological requirements or external environmental stimuli, it requires $\mathrm{A}$ to automatically suppress his excitement and let the appetite cool down to the rational level of emotion, as requires a rather high demand for A's willpower. Theoretically, appetite as a legitimate physiological requirement and basic human right, the suitable approach is reasonable catharsis, not long-term repression. If it is the management of sexual desire, from point of physiology and psychology, some religions' limitation upon the catharsis of sexual desire is unscientific. If A suppresses sexual desire for health or political needs, A has several options, one is to increase willpower, the other is to change external stimuli, or a combination of both, as previously analyzed. For example, A's libido reached its peak in fig.1, He is about to visit his old client D, when he suddenly gets a phone call, his son catches a high fever, A's heart is frustrated, sexual desire cools down. A's libido cools down, because the external stimuli changes passively, the son gets sick. In fact, people with mental knowledge can actively alter external stimuli to regulate their emotions.

The management of a certain emotional peak, is called the peak emotion management. The management of certain mood trough, is called the bottom emotion management. There are three methods in management control: feedforward control, site control, feedback control. A found that he and sex worker $\mathrm{H}$ had sexual excitement mental association, he can carry out feedforward control or forecasting management, to prevent the emergence of sexual excitement peak $\mathrm{W}$, that is, to take measures to prevent

\section{Volume 9 Issue 1, January 2020}




\section{International Journal of Science and Research (IJSR) \\ ISSN: 2319-7064}

ResearchGate Impact Factor (2018): 0.28 | SJIF (2018): 7.426

sexual excitement. For example, escaping mental environment or replacing external stimuli; If A does not use feedforward control, when sexual excitement peak W appears, A can also use the previous method or with the help of mental assistants, mental counselors; If site control fails, $\mathrm{A}$ and $\mathrm{H}$ have sex, A can only prevent the next turn of sexual excitement by feedback control. In ordinary environment, the peak or bottom of emotion should be avoided as far as possible. (1) excessive excitement or depression affects the perception of the subject, that is, increases the error of the subject's judgment upon reality, and grows the risk of loss; (2) excitement or depression is also the key point of war, both sides of war often try to induce their opponents to be excited or depressed, and then launch attack packets; (3) too much excitement or depression is also one of the internal ports to crisis. In conventional management, emotional management should ensure that the mental state runs near the median emotion or rational emotion Mo in Fig.1, so as to ensure the quality of the subject's reaction to environment.

But when the environment change needs the subject to be excited, then the subject should adjust emotion from peace to excitement, for instances, boxing players in a contest, warriors in a war. Even in those environments, excitement is moderate, not out of control.

Emotional inertia management is similar to addiction management. The reason of addiction is a weak will, low mental ability or great environmental disturbance, and the treatment of adolescent material addiction usually requires external force intervention.

\subsubsection{Group emotion management}

The internal emotion management is to improve emotional ability, to provide an internal mental environment with quality assurance for the development of the subject, influencing group psychology with appropriate emotion to form an external mental environment conducive to subject's development.

Proposition 1, the transmissibility of emotion. Any individual or group emotion, positive or negative, is transmissible in a particular social group and can have an impact on group psychology, which could be significant or insignificant.

According to proposition 1, people in certain social groups can confirm their emotional strategies according to their needs. For example, in a feudal political system, the health of political leaders is not easily disclosed because the feudal political system is sensitive to politicians and the spread of negative emotions can affect the stability of society as a whole. At the micro level, a teacher is not happy, while makes a smile, cheer up spirit to go to class, "make a good impression upon students, not to affect the teaching". Similarly, the first capacity of a shop assistant, salesperson or salesman is smile. In fact, the first capacity of business society is smile. Smile, make others happy, make everyone happy, happy customers are more likely to buy goods, happy friends are more likely offer help. "If everyone in a bad mood, how to talk about it? It's hard to talk" . From a socio-mental point of view, optimism is welcome, "he can bring happiness to everyone."

Proposition 2, emotion changeable. Any individual or group of emotions can change, and must change, while with difference in time and degree.

Proposition 1 is provided only with empirical proof, proposition 2 can be provided theoretical proof, just make a falsification upon the proposition "emotion invariant". Is it possible that the mood will remain unchangeable? According to the philosophical proposition, "things are changing", then a falsification is made toward the proposition "emotion invariant". The change of a subject's emotion may be due to internal needs, external subject's emotion influence, or the occurrence of objective events.

According to proposition 1 and proposition 2, social subjects can exert mental influence on related social groups. For example, the political reformists can propagate the idea of political reform through various ways, which shows that political reform generates more good than bad to society, and that the failure of reform will bring great welfare losses to society. Religious people can preach to society that the power of gods exist and gods protect social justice, so as to persuade society to be good. Subordinates irritate or misunderstand their superiors, and take appropriate measures to change their negative emotions. Similarly, there are business-oriented commercial advertising for consumers. "Don't worry about your superior bear side opinion against you, you can try to change his minds".

Proposition 3, the law of dyeing vat. Any individual emotion is bound to interact with environment, so the individual psychology takes on the characteristics of environment. Like a cloth in a dyeing vat, the degree of interaction between individual and environment depends on the nature of environment, the nature of individual, and the length of time.

The law of dyeing vat illustrates the interaction between environment and individual psychology. It also explains the mental differences between groups from different regions and different cultural backgrounds. According to the law of dyeing vat, managers can shift an important employee into a different region to actively change their staff. Alternatively, a large number of other ethnic residents will be transferred to a single ethnic area in order to change the cultural structure of the region. For example, Mao Zedong moved a large number of Han nationality residents to Xinjiang in the 1950s, thus reformed Xinjiang's ethnic structure and social cultural customs. It has enhanced understanding among different ethnics and promoted the unification of the Chinese nationalities. There is a great mental difference between the deserted land and the rosy market, as is the function from the law of dyeing vat. When a person walks in the city along a sex service street, sex excitement must be aroused in his heart, his mind is tested by the law of dyeing vat. In ancient China, the allusion of Mencius "three-moves of Mencius's mother" showed that human society had long been aware of the law of dyeing vat.

The law of dyeing vat can also be employed to explain mental inertia, incest, homosexuality, etc. The above three 
propositions are relevant.

\subsubsection{Emotion rigidity and emotion conflict}

Individuals may also encounter extreme external emotions, that is, external mental risks, such as emotional rigidity of external individuals, mental disorders or spiritual disorders.

Definition 2, the emotional rigidity. Individuals who have some mental inertia or are in mental disorder, mental stress, when integrated into groups, lack mental flexibility or show low dexterity in dealing with group interaction events, or even make an immediate overreaction due to a simple understanding upon the behavior of others. This emotional trait caused by certain mental inertia, mental disorder, or mental stress, is called emotional rigidity.

Emotional rigidity exists to varying degrees. Some people are subtle, some are serious. Generally speaking, the emotional rigidity of the elderly and young children is relatively heavy, and the uneducated are relatively heavier than the educated. Individuals with a single life experience would be heavier than people with abundant life experiences Emotional rigidity generally has a tendency of harm, hurts upon the subject himself or others. There are many reasons for emotional rigidity. (1) values are misplaced. Such as religious extremists, political and ideological extremists. For example, the ten-year cultural revolution in 1960s in China was mainly the result of mental rigidity caused by the misunderstanding upon values. Value orientation will play a primary role in attempting to influence group emotions. (2) insufficient knowledge stock, such as insufficient school education and unitary social experience. It is easy for such individuals to interpret the same phenomenon simply, then generate prejudice or hostility, increasing the risk of mental conflicts between different individuals. (3) Special life experience. A man who has been hunted down by a feudal rascal group for a long time, a drug lord who escapes the police, they are highly sensitive to the surrounding environment, they tend to regard non-offensive information as attacking information, then would overreact. (4) repressive political environment. People who live in feudal political system for a long time, because they are in a violent competition environment for a long time, it is easy to regard the misconduct of strangers as an attack, resulting in their counter-attack or hostile feelings, thus leading to conflicts. (5) fierce economic competition. The one-sided growth goal induces fierce business competition, which also leads to emotional rigidity, makes individual emotion break out irrationally, resulting in attacking behavior. As to current China, on the whole, rural residents have stronger mental rigidity than urban residents, the elderly have stronger mental rigidity than the middle-aged and young people, such as the rural people are more extreme, the elderly are more stubborn. Gangsters from underground society tend to employ violence and revenge, as is also a manifestation of emotional rigidity. First, they are easy to take the behavior of others as harm; second, they have the mental inertia of venting violence. Individuals will face greater uncertainty or conflict risk in unfamiliar mental environments because it is not easy to distinguish different mental characteristics concealed by similar appearance. Emotional rigidity also provides another explanation for caution in the feudal political system. Feudal violent rulers have the weakness of emotional rigidity and the inertia of violence venting.

Therefore, just as common management, the most important task of group emotion management is to identify the mental environment for the system, and then to formulate the correct mental strategy.

\subsubsection{Optimal emotion}

How do individuals optimize their emotions? How do managers optimize the mood of the group? Optimization is an important goal in the study of management economics, which can be introduced into mental management.

Definition 3, the optimal emotion. Optimal emotion refers to a state of mind in which individuals or groups gain a maximum utility. This state of mind is not static, it is the dynamic adjustment of the subject upon the external environment.

Definition 3 shows that a static optimal emotion could not attained by mental management, that is, there is no omnipotent emotion suitable for all environmental changes. It will be futile to try to get an omnipotent emotion. To obtain a maximum utility, the subject can only adjust dynamically along with environment change of and strive to obtain the dynamic optimum, that is, the mental management is also dynamic management. The acquisition of maximum utility is not only the responsibility of mental management, but also depends on various fields of personal management, such as political environment management, social relationship management, daily work management, physical health management and so on.

However, as to a specific point of time, there exists an optimal emotion to get a maximum utility for the subject (Fig.3). Fig.3 shows that the optimal emotion of the relevant subject at the moment is point $\mathrm{W}$, and the maximum utility at the specific moment is obtained by the subject at $\mathrm{W}$. The $\mathrm{E}$ in Fig.3 shows the mood moving toward Excitement, while the $\mathrm{P}$ indicates the Peaceful state, $\mathrm{D}$ indicates the emotion moving towards a Dismay, U represents the utility value.

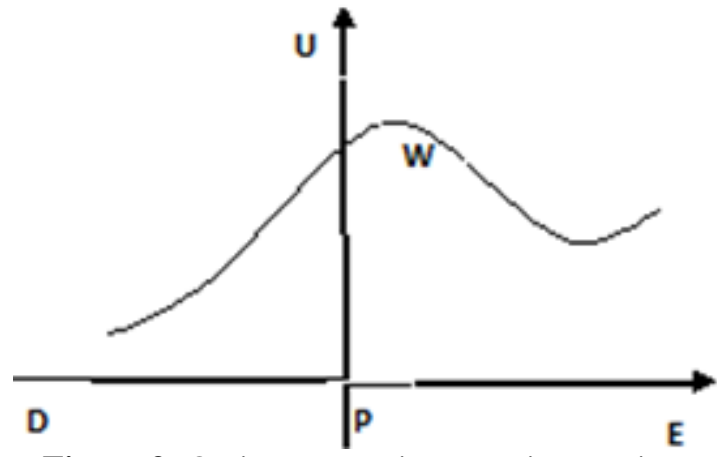

Figure 3: Optimum emotion at an instant time

What is the emotion satisfying the optimal utility depends on the judgment and decision of the subject. For example, before the spirit Beijing Erguotou, the alcoholic $M$ chooses venting, e.g. excitement, he thinks he could get the maximum utility by drinking Erguotou. $\mathrm{N}$ chooses repressing, $\mathrm{N}$ thinks that he could lose his minds after drinking, his own judgment might be affected, the quality of

Volume 9 Issue 1, January 2020 


\section{International Journal of Science and Research (IJSR) \\ ISSN: 2319-7064}

ResearchGate Impact Factor (2018): 0.28 | SJIF (2018): 7.426

work would be lost, the physical health could be endangered, so $\mathrm{N}$ decides to control alcohol. M's decision is for an instant maximum utility, N's decision is for a long term maximum utility, and their decisions are quite the opposite.

It should be pointed out that mental inertia, mental exercise and emotional management are related to each other. Mental exercise is an important means to overcome mental inertia and carry out emotional management, which is the basic content for mental management as well as the improvement of mental ability.

\section{Mental health management under circumstances interacting with special environment}

\subsection{Mental health management in a soft war environment}

When an individual is in a soft war environment, his mental ability will be tested. Espionage wars among different nations, the implicit violence competing for political benefits among different political groups in the same country [5], all are soft war. Mental war is an important part of war. The main attacking points of soft war cover: (1) desire attack, sexual desire or wealth desire, power desire; (2) attacking perception, such as attacking memory, creating illusion to the attacked, etc. (3) attacking willpower, such as terrorizing the attacked, creating mental confusion, etc. (4) attacking mental inertia, such as attacking life and work habits, hobbies, attacking the matter which an individual must do in a particular time or space, (5) infiltrating the corresponding social relation; (6) creating mental disturbance to make the subject deviate from rational emotion, induce the attacked to make wrong response, and so on.

Mental management in a soft war environment could not escape away from the general management principles, (1) identify the environment, recognize that the environment is a soft war environment or an environment of implicit violence, do a good internal mental early warning; (2) frequently study political environment, improve capacity for political judgment, fortify political stand and political will, in current China, strengthen "political consciousness, overall situation consciousness, core consciousness and leveling consciousness"; (3) preventing beauty trap or money trap; (4) cultivate a mental capacity with strength accompanied by flexibility, emptiness accompanied by entity, (5) carry out necessary anti-inertia training, track the attacking path of the attacking party, preventing mental inertia from being locked or ambushed by the attacker, (6) educating the relevant groups and preventing the attacker from infiltrating; (7) establish memos or use work assistants to improve the ability of information recognition.

Soft war is an invisible war, the contest is extremely fierce, not easy to defend, an untrained man would easily be attacked. Wang Yun deployed Diao Chan to attack Dong Zhuo in Chinese Three Kingdoms period[6], a typical beauty trap. Beauty trap has a history of thousands of years, familiar to everyone's ears, but still has an attacking capacity not declining, as may be due to two reasons: one is that it has a natural mental foundation, the other is, with history evolving, people may forget the methods of beauty trap.

\subsection{Mental forecasting under game context}

If two or more adversaries compete, how do you grasp the real purposes of your opponents? For example, commercial negotiations, political negotiations. To judge the psychology of opponents, there are five elements: (1) values; (2) the need of participants in the competition; (3) the strength contrast of each participant; (4) the information situation; (5) the stability of environment. There are two competitors, A and $\mathrm{B}$, whose game tables are as follows (Tab.3):

Table 3: Strategies for two rivals of a game

\begin{tabular}{|l|l|l|l|l|l|l|}
\hline & values & needs & strength & information & $\begin{array}{c}\text { Environment } \\
\text { stability }\end{array}$ & $\begin{array}{c}\text { Strategies or } \\
\text { price setting }\end{array}$ \\
\hline A & & & & & & \\
\hline B & & & & & & \\
\hline
\end{tabular}

If $\mathrm{A}$ inclines to fair distribution, he will not ask $\mathrm{B}$ for a high price even though his strength is superior, such as $90 \%$ of the total strength; or if A's information is insufficient, he does not understand the strength of B, he may ask B for low price for risk aversion; Or a pessimistic outlook upon environment, to get rid of risk, he may also ask B for a low price. When $\mathrm{B}$ makes mental prediction upon $\mathrm{A}$, it can first try to understand A's mental state and its environment background from A's formal or informal language, gets information as complete as possible, and gives a rational price according to the elements of Tab.3.

\section{Several Applied Mental Models}

Despite there are no omnipotent emotions, sages in human history had wanted to achieve a kind of "best state." It is also an important goal of mental management to adjust the internal state to the instant best or to approach that.

\subsection{Empty cup attitude, zero emotion}

The business society trains the staff, often says "empty cup mentality". As the name implies, the empty cup is empty, void, and has nothing within, indicating a humble heart. When you receive training, you have to be humble to the text book, to the lecturer, to the student, and the mind as transparent, null as a empty cup. If you think you know everything, there would be rejection mood, and the efficiency of the entire training process could be discounted. The idea of "zero emotion" is mainly employed in business negotiation, which means participants should not bring emotion to negotiation table, they should have no emotion, and their emotional state should be zero. If negotiators bear prejudice before negotiations, with significant differences from both sides at the beginning, the negotiation could encounter obstacles.

The application of empty-cup mentality and zero-emotion runs far beyond human resource training and business negotiation, they are widely employed in various fields of social interaction. In soft war environment, such mental 


\section{International Journal of Science and Research (IJSR) \\ ISSN: 2319-7064}

ResearchGate Impact Factor (2018): 0.28 | SJIF (2018): 7.426

application would be more. They provides concrete models for people how to stay rational and calm.

On the basis of both, the idea of "hot iron into water" could also be introduced. The red hot iron is suddenly put into cold water, which means to cool the fever and bring the subject back to rationality. In former text, A is passive to cool down his sexual want, as belongs to the case. While, mental management pursues active cooling for heated heart. The idea of "hot iron into water" is useful, and emotional overheating is an important cause for great loss.

Many philosophies and religious thoughts conform to the laws of mental science. In China, Bible of Changes proposes "modesty", Taoism advocates "water softness, and inaction" , Christianity and Islam encourage "modesty", Buddhism for "emptiness, no self". Although these concepts are different, they have an intersection or sharing truth with the idea "empty cup mentality, zero emotion" of business society.

According to the six indexes of mental ability in Tab.1, "empty cup mentality" and "zero emotion" are discussed for how to interface with the environment. These two concepts are more suitable for the mental management of ordinary environment. The related idea "hot iron into water" is mainly applicable to exciting management.

\subsection{Li Zongwu's "thick and dark" mental model}

Li Zongwu's Thick and Dark [7]was once banned. In peace time, if everyone's heart is thick and dark, social uncertainty hikes, social transaction costs rise, and social hidden violence would happen with high frequency. Therefore, both thick and dark should be prohibited by civilized society. From the military point of soft war, all intelligence personnel are thick and dark in state to state espionage. Therefore, Thick and Dark is a soft military work, thick and dark is a soft war environment mentality.

The thick and dark mental model is also a comprehensive model of environment orientation. Measured by the six indexes of mental ability, the thick and dark mentality has good strength, flexibility, recovering capacity, balance ability and intelligence. That is, most of the six major indicators of mental ability have very good performance. The reason is that from the point of soft military, its first concern is to protect itself, e.g, "self-beneficial". Thick and dark psychology has a wide range of application in practice. Commercial salesmen should have thick skin, love affairs demand thick skin, speech on stage needs thick face, singing on stage requires thick face, preventing social hooligans demand dark heart, and so on. Under the order of a traditional feudal society, the model of thick and dark mentality had more practical value.

From the point of whole society, under a civilized order, "no one wants to be offered thick and dark", so the values in Thick and Dark are not worth popularizing and propagating. From the perspective of mental science and personal development, the thick and dark mentality can be employed for the purpose of fairness and justice.
3.3 Wei Xiaobao's "dynamic mental model" in Jin Yong's work

Wei Xiaobao was a hero in Jin Yong's militants story[8] The Deer and The Cauldron. The mental model of Wei Xiaobao is a complicated dynamic mental model. He could be a hooligan, a liar, a servant, a killer, a versatile lover, a feudal king, a hero, a rich businessman, a sage, what kind of role he would play, as was decided upon the environment situations. He was a successful mental manager who could play different roles without mental conflict. From the six indicators of mental ability, the mental strength, flexibility, recovering capacity, dexterity, balance, and intelligence all are very high, and his thick and dark attribute seemed to have reached a perfect state. This is another type of Chinese feudal bureaucrats, 'gods coexisted with demon' behind a civilized appearance. In front of these bureaucrats, ordinary people suffering "Yang Naiwu, Pakchoi" type of injustice was not a surprise ("Yang Naiwu, Pakchoi" case was a major case of injustice in Chinese Qing Dynasty). Wei Xiaobao's mentality was the product of traditional feudal society, his dynamic mentality mode is not easy to appear in a civilized society, and within Wei Xiaobao himself, the components of justice occupied the majority.

In a business world, Wei Xiaobo's flexible changing minds, decision by circumstance orientation mentality, if for justice purposes, most of them are desirable.

\subsection{Decision by circumstance orientation in mental management}

There is an idea of decision by circumstance orientation in economics, which is suitable for personal mental management and is an important content of dynamic psychology. Mental management, for an individual with normal minds, can not obtain an omnipotent emotion under different circumstances, e.g, there is no emotion that can make the individual attain maximum utility in different environments. Therefore, regardless of quick or slow environment switching, the individual's mental management is dynamic management, e.g, a decision by circumstance orientation for the environment, the macro-economic decision by circumstance orientation is mainly feedback control, and the mental management decision by circumstance orientation could be a comprehensive employment of feedforward control, site-control and feedback control. The quicker the speed of environment switching, the higher requirement upon the mental dexterity. The slower the speed of environment switching, the higher requirement upon the mental strength to overcome mental inertia. The environment change will inevitably requires the subject to regard the mental system as an open system, "to implement the concept of open development", regarding the individual as a part of the whole environment, which has a great influence upon the mental ability.

The above four practical mental models have two common characteristics: (1) the mental inertia of the subject is very low, which accords with the philosophy of "openness" development, showing that the closed operation of "little ego" against the order of "big ego" will surely not work. "the trend of the world, grand and mighty, those complying

Volume 9 Issue 1, January 2020

www.ijsr.net

Licensed Under Creative Commons Attribution CC BY 


\section{International Journal of Science and Research (IJSR) \\ ISSN: 2319-7064}

ResearchGate Impact Factor (2018): 0.28 | SJIF (2018): 7.426

with it, will get prosperous, those perverse against it, will perish", as has a profound implication. It unveils that the driving effect of the mega-field upon ordinary individuals is also suitable to psychology. Breaching the law of mega-field movements is tantamount to going against the heaven, it is bound to get setbacks. So, Chinese ancestors had saying, "do the best, listen to the heaven". In addition to internal subjective desire, there are external constraints of the mega-field movement situation. Of course, there is no need to reject individual's exerting his own creativity. Under special environments, "push forward despite of impossibility". (2) all of them are born in the real environment, as proves that the mental ability can not escape the truth of "practice creates true knowledge". These two common points reveal mental science does not contradict philosophy, but is subordinated to philosophical principles.

\section{Conclusions}

Under a normal social order, an individual with normal intelligence, mental quality, physiological quality are the most important internal resource condition for his sustainable development. Mental health management is the only way to maintain the sustainability of mental resources. The study of mental health and mental management in a changing environment belongs to dynamic psychology. Personal mental health management is mainly to build good mental ability for teenagers, while for adults, mainly to prevent mental inertia and mental aging. To individuals of different age, mental exercise is important, which mainly targets improving or maintaining mental strength, flexibility, recovering capacity, dexterity, balance and intelligence. Emotion is transmissible, changeable, individual psychology interacts with environment, "those beside ink get black, those near cinnabar get red", they will abide the law of dyeing vat, a subject can influence a group emotion and improve external mental environment accordingly. To change a subject's emotion, the simulation technique altering or replacing external environment could be employed, and so on, but the most important thing depends on the subject's will effort at a certain emotional peak, passing through the peak, as is decided by the subject's mental strength. Negative mental inertia, emotional rigidity is a potential risk to the subject as well as the society, mental exercise will be helpful to eliminate inertia, reduce rigidity and improve flexibility. The mental management is a kind of management oriented to real environment, which is dynamic. Individual can not obtain an omnipotent emotion, but there is an instant optimal emotion for certain subject at special time, and mental management can also run dynamically to obtain a maximum utility for the subject, e.g, make decision by circumstance orientation in different environments, choosing different mentality. Li Zongwu's thick and dark mental model, Wei Xiaobao's dynamic mental model are products of feudal violence order, which are not easy to appear in a civilized society, and the negative side of their values should also be negated. But they have an important reference function to mental management in the intense commercial competition environment. The four models of mental practice show that the management of mental health follows philosophical truth and cannot violate the general principle of management.

\section{References}

[1] Luo Guicheng, Tan Bin, Zheng Shiqiao. Personal Quality Structure, Social Order and Long Term Curve of Personal Development [OL]. www.paper.edu.cn. 2009.

[2] Luo Guicheng, Luo Rundong. On Building of Personal Management, A Frontier Science [OL]. www.paper.edu.cn. 2008: 1-2.

[3] Taylor, James. Secret O' Life Album: JT; Professional experience of 25 years as a practicing clinical psychologist

[OL].1977.

http://mentalhealth.about.com/cs/stressmanagement/a/ whatismental.htm.

[4] Yu Xi-xiang, Wang Jian. A Summary of Mental Stress Studies [J]. Education For Chinese After-school. August 2008: 1353-1354.

[5] Luo Guicheng. Soft War, Social order and Personal Management $[\mathrm{J}]$. Journal of Zaozhuang University. 2016 (06): 66-76.

[6] Luo Guanzhong. Romance of Three Kingdoms[M]. Beijing: Knowledge Press, 1996.

[7] Li Zongwu. Thick and Dark[M]. Jilin: Jilin university press, 2009/08.

[8] Jin Yong. The Deer and The Cauldron[M]. Shanghai: SDX Joint Publishing Company, 1996.

[9] Luo Guicheng 1970-, male, a master on education, high lecturer of Bengbu University, China, inputs most of his efforts on PM, Xi Jinping Thoughts research, religion and social science.

[10] guichengluo@yahoo.com, luogc@bbc.edu.cn. 